\title{
Moment tensor inversion of early instrumental data: application to the 1917 High Tiber Valley, Monterchi earthquake
}

\author{
Fabrizio Bernardi ${ }^{1,{ }^{\star}}$, Maria Grazia Ciaccio ${ }^{2}$, Barbara Palombo ${ }^{1}$, Graziano Ferrari ${ }^{3}$ \\ ${ }^{1}$ Istituto Nazionale di Geofisica e Vulcanologia, Centro Nazionale Terremoti, Rome, Italy \\ ${ }^{2}$ Istituto Nazionale di Geofisica e Vulcanologia, Sezione Roma 1, Rome, Italy \\ ${ }^{3}$ Istituto Nazionale di Geofisica e Vulcanologia, Sezione di Bologna, Bologna, Italy
}

\section{Article history}

Received August 7, 2015; accepted May 25, 2016.

Subject classification:

Moment tensor, Historical seismology, Waveform modelling, High Tiber Valley, Macroseismic, Re-location, Magnitude.

\begin{abstract}
In this paper we present a new study on the High Tiber Valley earthquake occurred on April 26, 1917. Using the digitized data from mechanical seismograph records, we computed the source parameters like focal mechanism and moment magnitude from moment tensor (MT). The study of historical earthquakes from an instrumental perspective is crucial because of the complexity of problems associated with the study of seismograms of moderate to large earthquakes occurred from the late 19th century until the early 1960s. Since historical earthquake records show significant uncertainties in phase arrival times and have been recorded by seismograph generally with short natural period, we developed a code to compute the MT based on a forward modeling technique, which uses the amplitude spectra of the full waveform length and the first P-arrival polarities to constrain the P-and T-axes. The best solution is determined by the best fit between the observed and synthetic amplitude spectra and from the coherency between the observed and the theoretical first P-arrival polarities. The 1917 High Tiber Valley earthquake is one of the most important 20th century earthquake occurred in the Italian Peninsula for which the focal mechanism and moment magnitude from seismic records are not available. Additionally, we apply a multidisciplinary approach to characterize the source of this earthquake, combining instrumental, macroseismic, geological and tectonic data and investigations. The computed MT results in a north-south normal fault mechanism (strike: $147^{\circ}$, dip: $29^{\circ}$, slip: $-94^{\circ}$ ), which is consistent with the strike estimated from the macroseismic data $\left(157^{\circ}\right)$. The moment magnitude calculated from the MT and that derived from the macroseismic data are $M_{w}=5.5 \pm 0.2$ and $M_{w}=5.9 \pm 0.1$, respectively.
\end{abstract}

\section{The 1917 High Tiber Valley earthquake}

In April 1917, a seismic swarm occurred in the Sansepolcro basin in the High Tiber Valley, close to Monterchi and Citerna in central Italy (Figure 1). The largest event, which occurred on April 26, 1917, struck part of the High Tiber Valley; the earthquake signifi- cantly damaged 26 villages and resulted in 20 deaths and 30 additional injuries. The most damaged villages were Monterchi and Citerna (Figure 2). The Catalogue of strong earthquakes in Italy (CFTI4med; see Data and sharing resources) shows an epicentral intensity between IX and X degrees of the Mercalli Càncani Sieberg scale (MCS) and reports a $\mathrm{M}_{\mathrm{w}}=5.8$ estimated with the Boxer 3.3 code [Gasperini et al. 1999, Gasperini 2004, Gasperini 2008] from the areal extent of the intensity point distribution.

New parameters of the 1917 earthquake have been estimated with the newly released Boxer 4.0 code [Gasperini et al. 2010]. In particular, Boxer 4.0 allows the determination of earthquake locations using both the barycenter method (method 0 ), as in previous versions, and a new approach with 6 more settings (methods 1-6) based on the maximization of the likelihood function of the "extended" log-linear attenuation equation [Pasolini et al. 2008] with observed intensity data (Table 1). Method 0 defines the barycenter of the area of higher damage, whereas methods 1 to 6 represent the radiation centers of the seismic energy with different fixed parameters. The Gasperini et al. [2010] approach allows for assessing the magnitude from macroseismic data and for estimating the dimensions (length and width) of the source using the relations of Wells and Coppersmith [1994].

Finally, the assessment of the seismogenic fault orientation [Gasperini et al. 1999] allows the plotting of a rectangular representation of the source ("box") as the projection on the horizontal surface of the possible seismogenic fault plane. For all the parameters (i.e., epicentral location and intensity, magnitude, and fault orientation), uncertainties are computed by using i) for- 


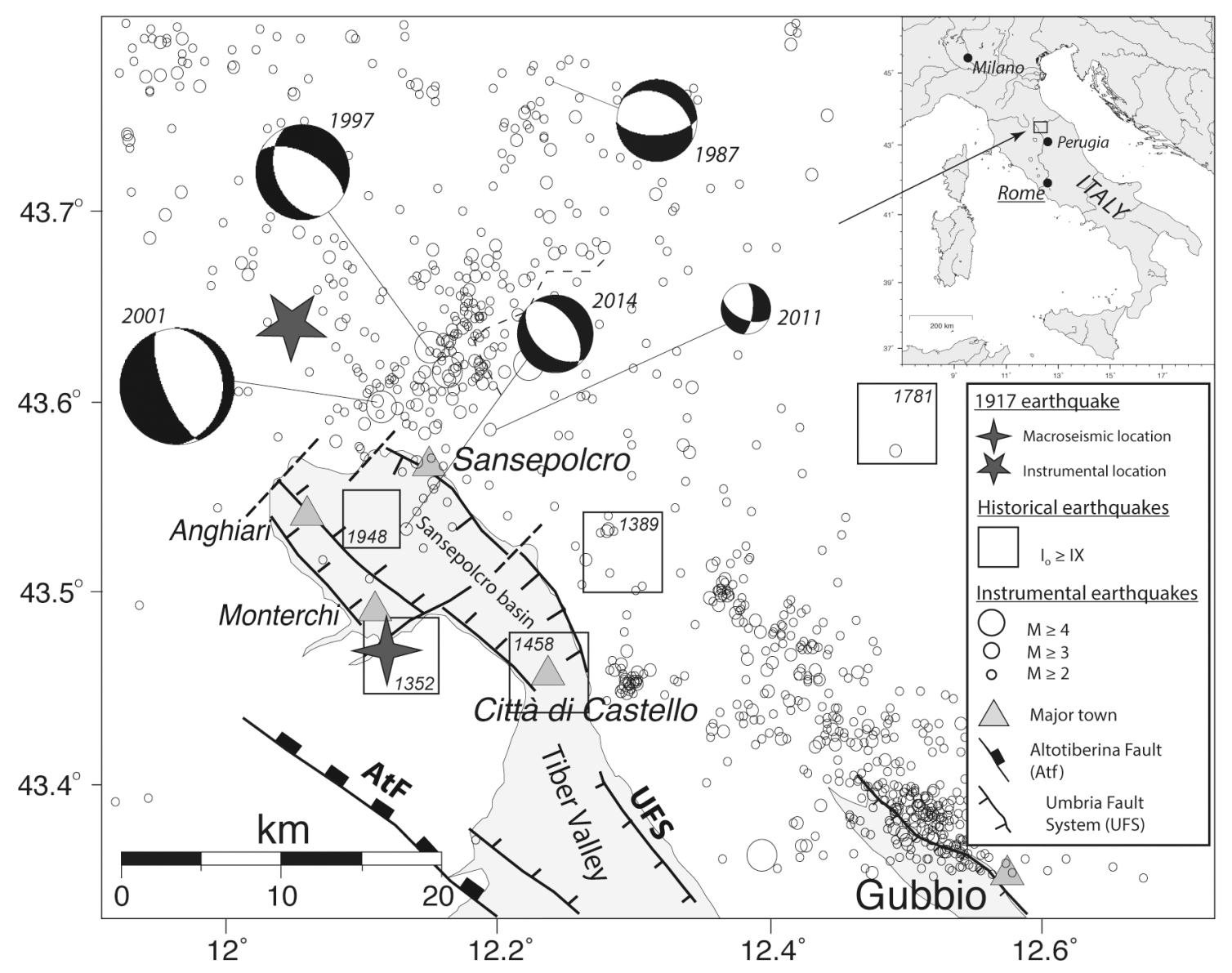

Figure 1. Location of the region and structural sketch map showing the major extensional faults: the Altotiberina Fault (AtF) and the Umbria Fault System (UFS), focal mechanisms refers to most recent events for which a moment tensor solution is available; thin line squares refers to the major historical events (year of the event occurrence inside the square); open dots refers to the instrumental earthquakes with magnitude $M \geq 2$. The grey filled stars refer to the macroseismic and to the instrumental epicenter location of the 1917 Monterchi earthquake computed in this study.

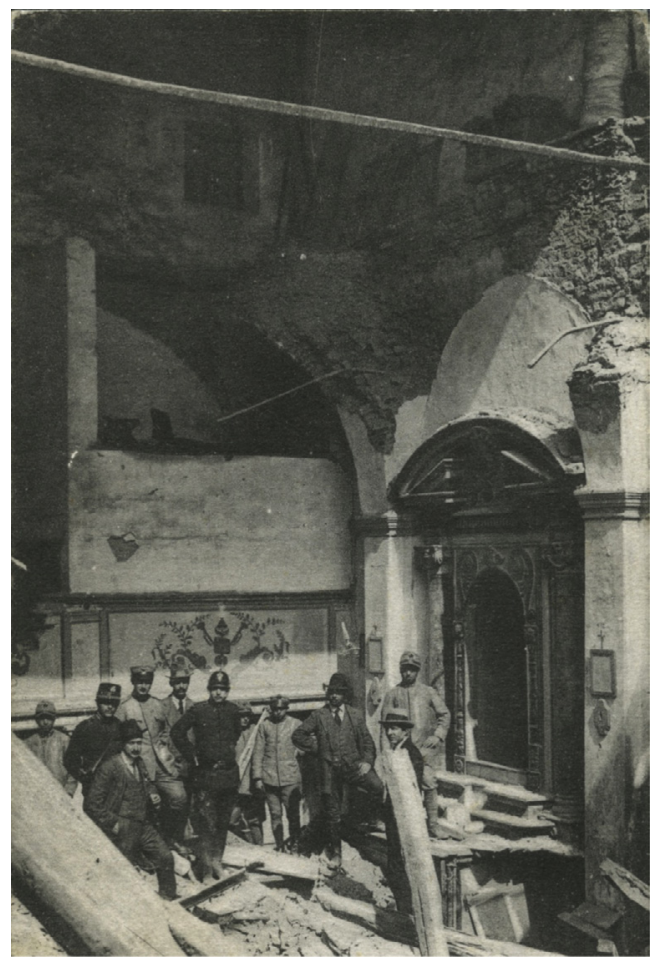

Figure 2. The very ancient church of San Giacomo of Citerna heavily damaged by the earthquake of April 26, 1917. mal methods, such as a variance/ covariance matrix by inverting the finite-difference Hessian of the log-likelihood function at its maximum or as the standard deviation of the parameter averages and ii) empirical methods based on bootstrap simulations. All estimated parameters of the 1917 High Tiber Valley earthquake are summarized on Table 2 and plotted on Figure 3.

All the epicenters calculated with methods 0 to 4 are clustered in an area approximately $1 \mathrm{~km}$ in radius, whereas the two epicenters calculated with methods 5 and 6 are located $3-5 \mathrm{~km}$ from the others. All methods estimate a macroseismic magnitude $\left(\mathrm{M}_{\mathrm{w}}\right)$ of 5.9. The epicentral intensity (Io) for methods 0 and 4 to 6 have uncertainties from IX to X MCS degrees, whereas the remaining methods estimate an Io $=$ VII-VIII. These last solutions have been discarded because they underestimate this parameter. Indeed, at least 12 localities have been classified as intensity VIII or greater. Of the remaining epicenter estimates, method 4 produces the minimum uncertainty in the coordinates and error ellipse (Table 2, Figure 3); we adopted this solution. As regard the strike of the source, we adopted the solution of the method $4\left(157^{\circ}\right)$ although both its bootstrap and 


\begin{tabular}{clll}
\hline Method no. & Method type & Estimated parameters & Fixed parameters \\
\hline 0 & Barycenter & Lat $_{\mathrm{E}}, \operatorname{Lon}_{\mathrm{E}}, \mathrm{h}$ & \\
1 & Att. equation & $\operatorname{Lat}_{\mathrm{E}}, \operatorname{Lon}_{\mathrm{E}}$ & \\
2 & Att. equation & $\mathrm{Lat}_{\mathrm{E}}, \operatorname{Lon}_{\mathrm{E}}, \mathrm{h}$ & $\mathrm{I}, \mathrm{b}$ \\
3 & Att. equation & $\mathrm{Lat}_{\mathrm{E}}, \operatorname{Lon}_{\mathrm{E}}, \mathrm{I}_{\mathrm{E}}$ & $\mathrm{h}, \mathrm{a}, \mathrm{b}$ \\
4 & Att. equation & $\operatorname{Lat}_{\mathrm{E}}, \operatorname{Lon}_{\mathrm{E}}, \mathrm{h}, \mathrm{I}_{\mathrm{E}}$ & $\mathrm{a}, \mathrm{b}$ \\
5 & Att. equation & $\operatorname{Lat}_{\mathrm{E}}, \operatorname{Lon}_{\mathrm{E}}, \mathrm{h}, \mathrm{I}_{\mathrm{E}}, \mathrm{a}$ & $\mathrm{b}$ \\
6 & Att. equation & $\operatorname{Lat}_{\mathrm{E}}, \operatorname{Lon}_{\mathrm{E}}, \mathrm{h}, \mathrm{I}_{\mathrm{E}}, \mathrm{a}, \mathrm{b}$ & \\
\hline
\end{tabular}

Table 1. Methods to locate the hypocenter of the version 4.0 of Boxer code [Gasperini et al. 2010] and estimated parameters. The methods maximize a log-likelihood function for a dataset of intensity observations with respect to the six unknown parameters. $\mathrm{I}_{\mathrm{E}}$ : epicentral intensity; h: hypocentral depth (for the method 0 the depth is computed by Musson [1996]); "a", and "b", respectively: linear and logarithmic coefficients of the extended attenuation equation [Pasolini et al. 2008]. See formulae 13 and 14 of Gasperini et al. [2010] for more details.

\begin{tabular}{cccccc}
\hline $\begin{array}{c}\text { Method } \\
\text { no. }\end{array}$ & $\begin{array}{c}\text { Latitude }\left({ }^{\circ}\right) \\
( \pm \mathbf{b s t} ; \mathbf{f m}, \mathbf{k m})\end{array}$ & $\begin{array}{c}\text { Longitude }\left({ }^{\circ}\right) \\
( \pm \mathbf{b s t} ; \mathbf{f m}, \mathbf{k m})\end{array}$ & $\begin{array}{c}\mathbf{M}_{\mathbf{w}} \\
( \pm \mathbf{b s t} ; \mathbf{f m})\end{array}$ & $\begin{array}{c}\text { Azimuth }\left(^{\circ}\right) \\
( \pm \mathbf{b s t} ; \mathbf{f m})\end{array}$ & $\begin{array}{c}\text { Io } \\
( \pm \mathbf{b s t} ; \mathbf{f m})\end{array}$ \\
\hline 0 & $43.467(1.566 ; 2.856)$ & $12.129(1.052 ; 1.370)$ & $5.91(0.07 ; 0.12)$ & $150.6(17.4 ; 18.2)$ & $9.5(0.2 ;-)$ \\
1 & $43.460(0.739 ; 1.326)$ & $12.124(0.562 ; 1.320)$ & $5.92(0.02 ; 0.12)$ & $152.7(74.2 ; 14.2)$ & $7.3(0.1 ;-)$ \\
2 & $43.462(0.720 ; 1.239)$ & $12.124(0.562 ; 1.223)$ & $5.92(0.02 ; 0.12)$ & $155.6(98.9 ; 16.8)$ & $7.3(0.1 ;-)$ \\
3 & $43.460(0.744 ; 1.333)$ & $12.124(0.563 ; 1.321)$ & $5.92(0.02 ; 0.12)$ & $152.8(74.5 ; 14.2)$ & $7.3(0.1 ; 0.1)$ \\
4 & $43.468(0.722 ; 0.909)$ & $12.122(0.512 ; 0.847)$ & $5.91(0.02 ; 0.12)$ & $156.8(86.9 ; 18.8)$ & $9.0(0.1 ; 1.0)$ \\
5 & $43.448(1.662 ; 1.366)$ & $12.134(0.665 ; 0.950)$ & $5.94(0.02 ; 0.13)$ & $150.3(29.7 ; 8.1)$ & $9.6(0.2 ; 1.8)$ \\
6 & $43.432(1.807 ; 1.330)$ & $12.136(0.864 ; 1.283)$ & $5.94(0.02 ; 0.13)$ & $158.4(13.4 ; 5.65)$ & $9.5(0.7 ; 0.9)$ \\
\hline
\end{tabular}

Table 2. Macroseismic parameters obtained from the intensity dataset using different methods supplied by Boxer, with associated bootstrap (bst) and formal (frm) uncertainties at $90 \%$ confidence level [Gasperini et al. 2010].

formal uncentainties are the larger.

Finally, combining the macroseismic-derived magnitude and source orientation with the empirical relations of Wells and Coppersmith [1994] we derived a length and a width of 11.2 and $7.6 \mathrm{~km}$, respectively, of the 1917 Monterchi earthquake source (Figure 3).

\section{Seismotectonic context}

The Sansepolcro basin is a NW-SE elongated basin presently occupied by the northernmost part of the High Tiber Valley located north of the Città di Castello (about $30 \mathrm{~km}$ toward NW of Gubbio and $80 \mathrm{~km} \mathrm{SE}$ with respect of Florenz). It is part of the active extensional belt located along a NNW-SSE trending belt from northern Tuscany to northern Calabria [Chiarabba et al. 2005, Ciaccio et al. 2006], where most of the upper crust seismicity of the Italian peninsula occurred. Scarce instrumental seismicity $(\mathrm{M}>2.5)$ compared to the adjacent areas was recorded below the Sansepolcro basin by the national seismic network. The areas towards the NW (Sansepolcro) and towards the SE (south of Città di Castello), have been struck by diffuse and frequent earthquakes (see Data and sharing resources:

\section{ISIDe and CSI).}

The Sansepolcro basin was generated as a result of a complex extensional fault system consisting of a lowangle normal fault (LANF) with a dip $<30^{\circ}$, a NE-dipping master Altotiberina Fault (AtF), and synthetic and antithetic splays bordering the opposite flanks of the basin; the NE-dipping synthetic splays of the AtF, i.e., the Anghiari fault, dips approximately $30^{\circ}$, whereas the Sansepolcro SW-dipping fault dips approximately $40^{\circ}$ and joins the AtF trace at a depth of approximately $3 \mathrm{~km}$ [Barchi and Ciaccio 2009]. The AtF has been active at least since the Late Pliocene, affecting the upper crust of this portion of the northern Apennines [Barchi et al. 1998], and it is part of a wider active fault system that runs NW-SE along the whole Apennines, from the Garfagnana Lunigiana region to the Valle Umbra Basin [Boncio and Lavecchia 2000, Mirabella et al. 2011].

The AtF bounds the western flank of the High Tiber Quaternary basin and has accumulated a minimum time-averaged long-term slip rate of approximately 1-3 mm/year in the last 2 Myear [Collettini and Holdsworth 2004, Mirabella et al. 2011]. The AtF-related seismicity shows a nearly constant rate of earth- 


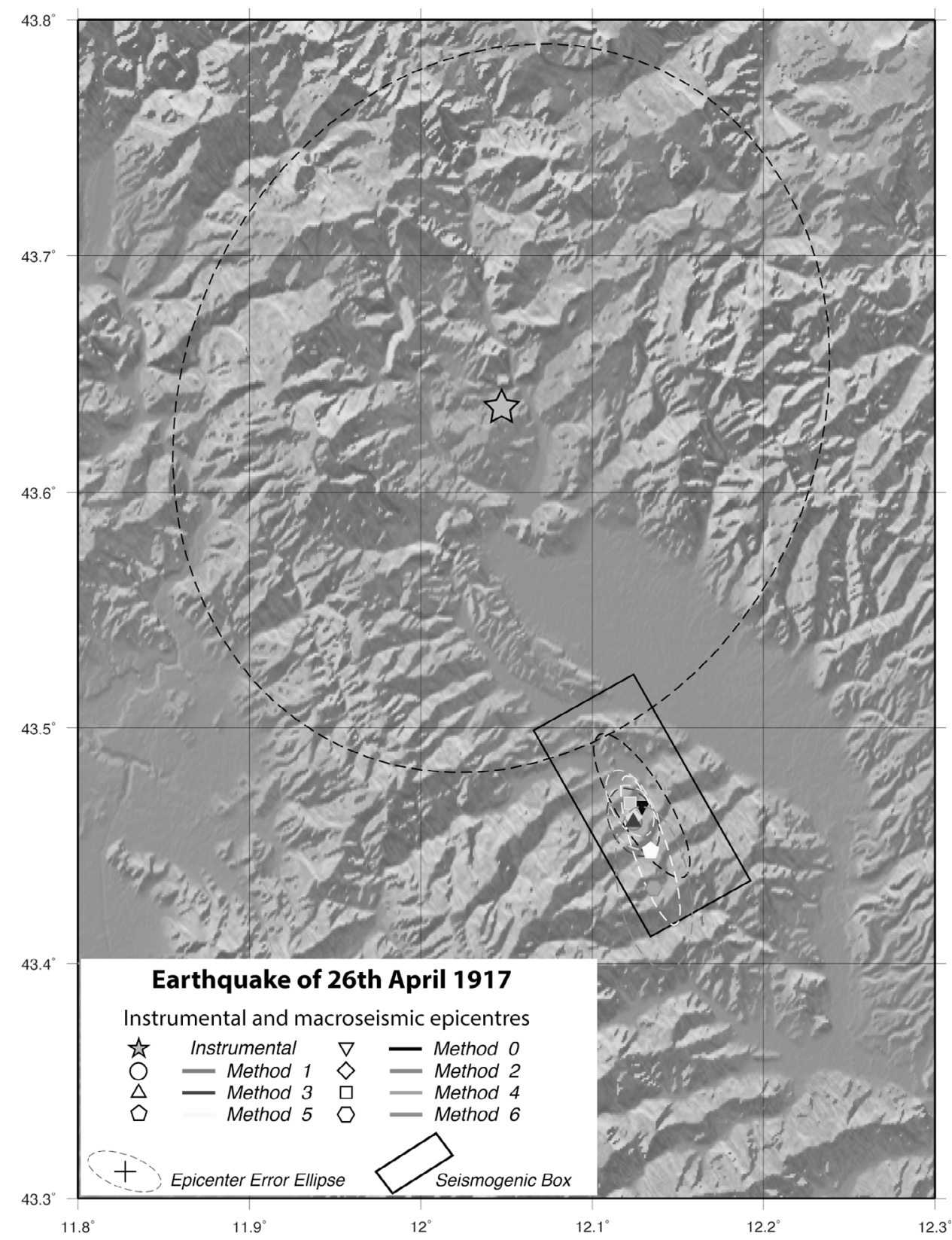

Figure 3. Comparison of the instrumental and macroseismic locations of the epicenter of 1917's earthquake.

quake production, with 3 events per day (ML 2.3).

The area north of Sansepolcro has been struck by moderate seismicity and by different minor sequences recorded by the Italian national seismic network (Figure 1), of which the 2014, 2011, 2001 and 1997 earthquakes $\left(\mathrm{M}_{\mathrm{w}}=3.6, \mathrm{M}_{\mathrm{w}}=3.3, \mathrm{M}_{\mathrm{w}}=4.7\right.$ and $\mathrm{M}_{\mathrm{w}}=4.4$, respectively) display SW-NE extension [Ciaccio et al. 2006, Scognamiglio et al. 2009]. In particular, the seismicity distribution of the 1997 sequence developed on a high-angle SW-dipping structure that could be interpreted as an antithetic fault to the AtF; the 2001 mainshock was localized at a depth of $5.5 \mathrm{~km}$ and displays a normal-fault mechanism with a NW-SE strike and a low-angle rupture plane $\left(21^{\circ}\right)$ dipping to the NE [Ciaccio et al. 2006, Piccinini et al. 2009].

The area south of Sansepolcro, through Gubbio up to Norcia (about $30 \mathrm{~km}$ and $100 \mathrm{~km} \mathrm{SE}$ with respect Città di Castello, respectively), is characterized by welldocumented historical and instrumental seismicity. The recent major earthquakes (NNW-SSE trend) are located within the intramountain basins, with a focal depth between 6 and $10 \mathrm{~km}$ and an extensional focal mechanism (Figure 1). The interpretation of seismic reflection profiles shows the presence of the LANF with associated high-angle antithetic structures. The instrumental seismicity aligns well with the trajectory of the AtF normal fault. These data lead some authors to attribute the strongest earthquakes of the region to the west-dipping normal faults antithetical to the AtF [Barchi et al. 1998, Boncio and Lavecchia 2000, DISS (see Data and sharing resources), Basili et al. 2008], but they also show that much of the ongoing deformation 
$-10^{\circ}-8^{\circ}-6^{\circ}-4^{\circ}-2^{\circ} 0^{\circ} 2^{\circ} 4^{\circ} 6^{\circ} 8^{\circ} 10^{\circ} 12^{\circ} 14^{\circ} 16^{\circ} 18^{\circ} 20^{\circ} 22^{\circ} 24^{\circ} 26^{\circ} 28^{\circ} 30^{\circ} 32^{\circ} 34^{\circ} 36^{\circ}$

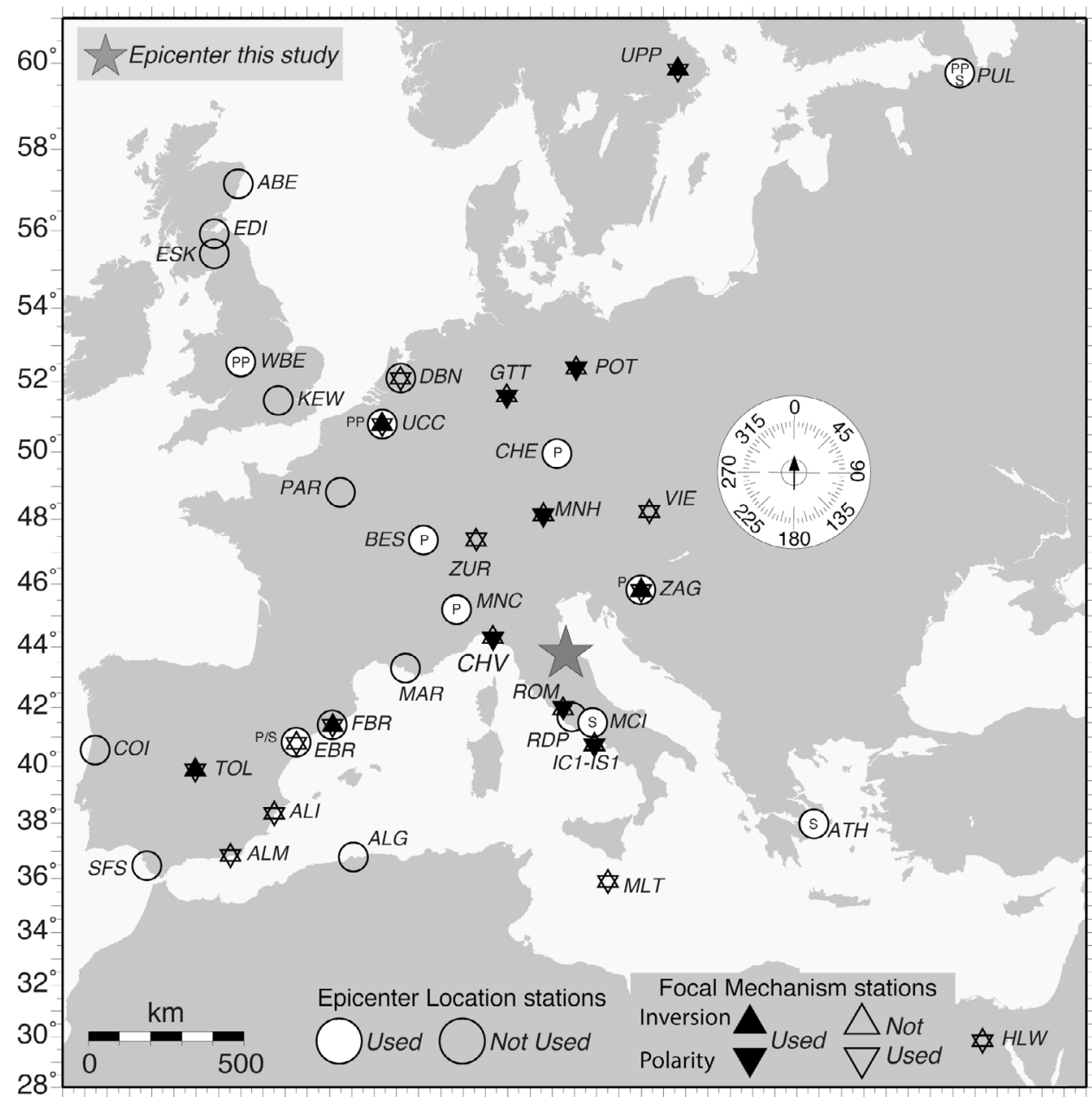

Figure 4. Map of the stations that recorded the seismograms used for the MT calculation.

is released through diffuse microseismicity and aseismic slip generated along the AtF surface [Piccinini et al. 2003, Chiaraluce et al. 2007].

Both the AtF and its high-angle splays are still active, as suggested by combined geological and geomorphological evidence. The historical seismicity of the area (i.e., the 1352 Monterchi, the 1389 Boccaserriola, the 1458 Città di Castello, the 1781 Cagliese and the 1917 Monterchi-Citerna earthquakes) can be reasonably associated with these faults; however, the available data do not constrain an unambiguous association between the single structural elements and the major earthquakes. Brozzetti et al. [2009] proposed that some of these historical earthquakes would be generated by segments of the AtF located at different depths and by the NE-dipping faults splaying out from them.

\section{Relocation and focal mechanism estimation from instrumental data}

For the April 26, 1917 earthquake, the scans of 61 recordings from 21 different stations (Figure 4) are available in the digital archives of the Sismos project [Michelini et al. 2005]. The Sismos project (see Data and sharing resources) was initiated in 2001 by the Istituto Nazionale di Geofisica e Vulcanologia. It involves scanning, archiving and distributing historical seismograms scans, station bulletins, log books, and related information retrieved from Italian observatories, dating as far back as 1895 [Michelini et al. 2005]. Sismos has already retrieved and processed seismograms written for approximately one thousand strong earthquakes that occurred in the Euro-Mediterranean area from the early 20th century [Ferrari and Pino 2003, Michelini et al. 2005].

Thirty-five arrival time readings of seismic waves (20 P and $15 \mathrm{~S}$ phases) reported by Cavasino [1927] have been checked from the available scanned recordings.

To relocate the 1917 earthquake and estimate the associated location uncertainty ellipse at $90 \%$ confidence (Figure 5), we used the fully nonlinear earthquake location package NonLinLoc (NLL; Lomax [2005]) with an equal differential time (EDT) misfit function. The code performs a probabilistic location of the hypocenter (Figure 5) quantified by a probability density function (PDF) in a 3D space. The PDF is obtained by means of an equal differential time formulation of the likelihood function and contains the calculated and ob- 


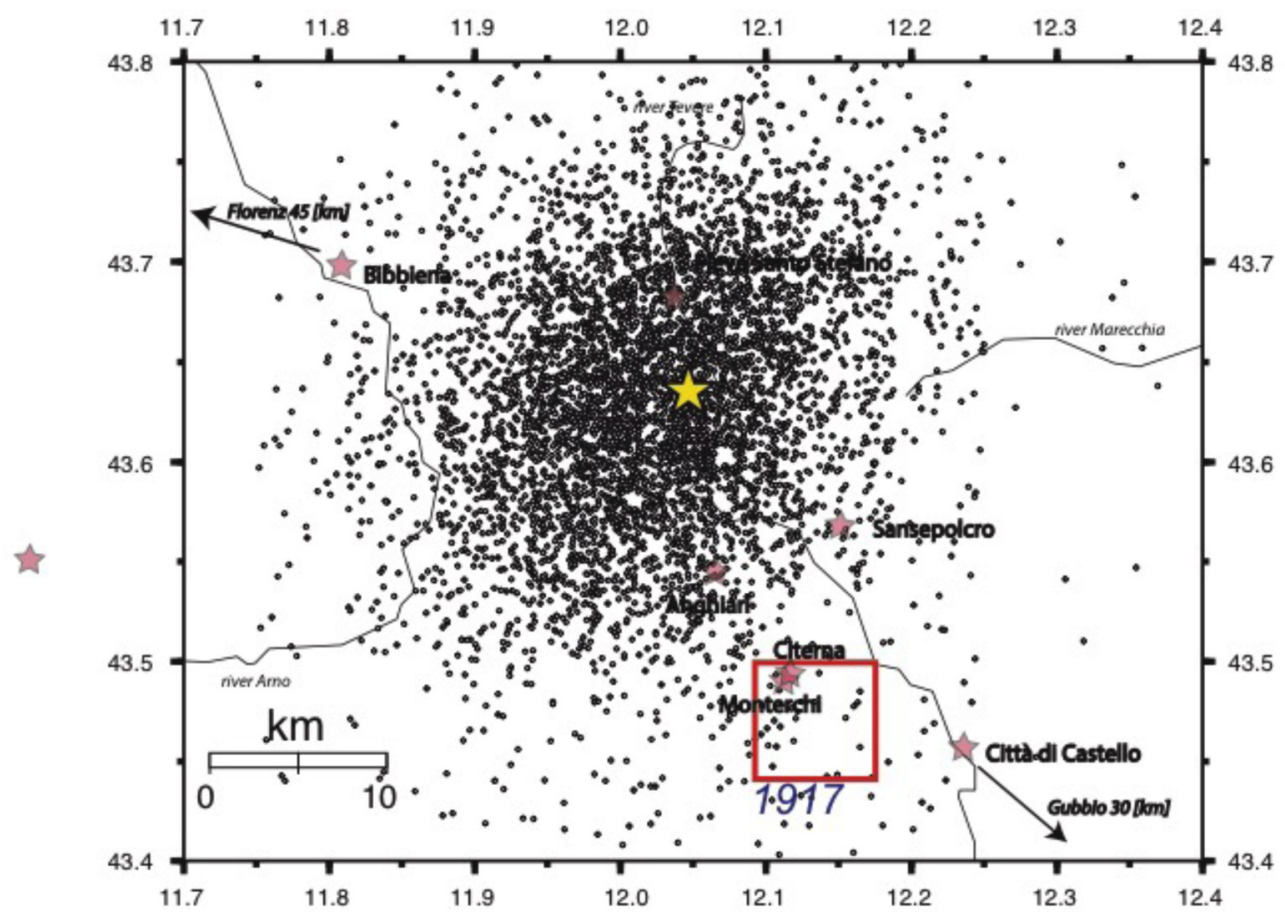

Figure 5. Instrumental epicenter of the 1917 Monterchi event (star) computed using NonLinLoc program. The PDF is represented by the clouds of points.

served differences between two stations, summed over all observations pairs. We adopted the ak135 model [Kennett 2005] for teleseismic phases and a standard Italian crustal model [DISS (see Data and sharing resources), Basili et al. 1984] for local phases.

The final solution was obtained after 3 iterations, using 12 phases ( $7 \mathrm{P}$ and $5 \mathrm{~S}$ ) and 12 stations (of the 24 available) with a maximum azimuthal gap of $107^{\circ}$ (Table 3, Figure 5). The arrival phases were automatically re-associated, and the outliers were eliminated during each iteration. Because of the EDT function [Lomax 2005], however, this method is not very sensitive to the presence of outliers.

Hypocenter is located at $12.05^{\circ}$ of longitude, $43.64^{\circ}$ of latitude and $5 \mathrm{~km}$ of depth, with uncertainties of 17 $\mathrm{km}$ in horizontal and $5 \mathrm{~km}$ in vertical [Lomax 2005]. Although a small number of phases was used to locate the earthquake, the horizontal location uncertainty is coherent with the uncertainty location produced by NonLinLoc [Lomax 2005] for recent global earthquakes localized using modern digital broadband seismic sta- tions [Bernardi et al. 2015].

The new location is approximately $18 \mathrm{~km}$ north of Monterchi, in the region where a seismic sequence occurred in 2001 (Figure 1) on the adjacent northern part of the Sansepolcro, especially in the region where these seismic sequences occurred.

\section{Moment tensor inversion method}

The scientific use of historical seismograms before the installation of the World-wide standard seismographic network (WWSSN) in the early 1960s is limited by the instrumental characteristics (instrument response and magnification) of the seismographs working at that time and by the fact that such data are often not available.

Due to these limitations, the moment tensor inversion procedure used for earthquakes recorded by historical seismographs is significantly different from that used for modern events. More specifically, the MT inversion of old seismograms faces difficulties related to the characteristics of early mechanical and electro-

\begin{tabular}{|c|c|c|c|c|c|c|c|}
\hline Origin time & Latitude & Longitude & Depth & str/dip/rake & $\mathrm{M}_{0}[\mathrm{Nm}]$ & $\mathbf{M}_{\mathbf{w}}^{*}$ & $\mathbf{M}_{s}$ \\
\hline $\begin{array}{c}19170426 \\
09: 35: 59\end{array}$ & 43.64 & 12.05 & 5.0 & $\begin{array}{c}\text { NP1: } \\
147 / 29 /-94\end{array}$ & $1.7 \mathrm{e}^{17}$ & 5.5 & 5.0 \\
\hline & & & & $\begin{array}{c}\text { NP2: } \\
331 / 42 /-88\end{array}$ & & & \\
\hline
\end{tabular}

Table 3. Instrumental epicenter location computed with NonLinLoc [Lomax 2005] and main MT solution parameters for the 1917 earthquake. $M_{w}$ following Kanamori [1977]. 
magnetic seismometers, recorded on smoked- and photopaper, respectively, which are significantly different from digital broadband seismometers. The main differences include frequency range sensitivity, magnification, recording quality, clock precision, and recording size, summarized as follows:

i) Frequency range sensitivity: Digital broadband seismometers are generally sensitive to a wide range of frequency, generally between 0.01 and $10 \mathrm{~Hz}$; in this range of frequency, the instrument response is mainly flat. Mechanical seismometers (e.g., Wiechert) are sensitive to a very narrow frequency (approximately 0.1 $\mathrm{Hz}$ ), and electromagnetic seismometers (e.g., Galitzin) are sensitive to a frequency range of $0.04-0.1 \mathrm{~Hz}$. The instrument response decays slower with respect to the response of mechanical seismometers but is still not flat [Bernardi et al. 2005]. The narrow and short- to middle-range sensitivity response of the early mechanical and electromagnetic seismometers indicates that seismic phases with long periods are not well recorded and resolved in the seismograms.

ii) Magnification. The ground velocity magnification of modern broadband seismometers is high enough (i.e., $10^{10}$ and higher) in contrast to that of mechanical seismometers, which is between 50 and 200 at the seismometer's natural frequency [Bernardi et al. 2005], and that of electromagnetic seismometers, which is generally between 200 and 800 [Bernardi et al. 2005].

As consequence of the limited frequency range sensitivities and low magnification of the early mechanical and electromagnetic seismometers, seismic phases may not be well resolved in the seismograms.

iii) Quality of the recordings. Mechanical and electromagnetic seismometers saturate faster than broadband seismometers because they have lower dynamics compared to digital ones. Most of the low-quality problems of early seismometers involve the recording support (i.e. smoked- and photo-paper) and the recording device. When strong ground or velocity displacements occur, the recording system (nib for mechanical seismographs and light beam for galvanometric ones) causes weak or absent traces on the recordings of stations close to the epicenter. This results into significant seismograms gaps.

iv) Clock precision and size of the recording. The time clock of recording systems in 1917 was driven by radio signals and synchronized by very few observatories and seismic stations worldwide; thus, for most of the observatories, clock synchronization uncertainty was greater than a few seconds.

The low speed of the recording drum (15 or 30 millimetres/min) of most of the early seismographs makes the waveform recording more sensitive to drum speed variations. Furthermore, when the clock synchronization was the most precise, small variations in the recording drum speed and the small size of the recordings may have introduced distortion into the phase arrival times.

The short-middle period sensitivity of the seismometers implies the use of short and moderate periods for waveform modeling. Earth system models for regional and global scales for such periods are generally not available. A source-path velocity model should be calibrated for each earthquake and each source-receiver configuration.

The combination of the above-described points (i.e., iii and iv) implies that the amplitude and phase velocity may present distortions. For these reasons, we prefer to approach the moment tensor computation in the frequency spectrum domain than in the time domain. Spectrum amplitudes are less sensitive to Earth model heterogeneities than phase velocities. We thus invert the waveforms and synthetic seismograms in the frequency spectrum domain and then use the $\mathrm{P}$ wave first arrival polarities to constrain the $\mathrm{P}$ - and $\mathrm{T}$ - axes.

We thus use amplitude power spectra within the instrument frequency range sensitivity, assuming that the power spectra shapes and the polarities are not significantly affected by crustal and lithospheric structures at these frequencies. This assumption allows to i) use the seismic recording within the larger sensitivity band of the instruments; ii) analyze moderate earthquakes recorded at local/regional distances; iii) use regional and/or global 1D Earth models for the entire dataset.

Our approach is similar to that of Zaradnik et al. [2001] and Okal and Reymond [2003]. Zaradnik et al. [2001] proposed a method for weak earthquakes, inverting higher-frequency seismic signals recorded at local distances from digital seismometers in the frequency domain. This approach implies a very dense network of stations close to the source, which is impractical given the very sparse historical seismic networks. Okal and Reymond [2003] proposed a method for large historical earthquakes recorded with sparse networks, inverting the seismic signal in the time domain and using the first $\mathrm{P}$-wave arrival polarities to constrain the $\mathrm{P}$ - and $\mathrm{T}$ - axes.

As previously mentioned, the sensitivity of all mechanical and most electromagnetic seismometers is low, which suggests that the Okal and Reymond method is suitable for large earthquakes recorded at teleseismic distances but not for moderate earthquakes recorded at regional distances, as in our case.

We thus developed a code suitable for moderate historical earthquakes recorded on sparse networks by inverting the waveforms in the spectral domain, using 
Date: 14.09.03 Time:21:42:53.3 Lat:44.390 Long:11.510

Plane (strike/dip/slip)

TEST NP1: 199/44/40 NP2: 78/63/127

CMT NP1: 264/31/98 NP2: 74/60/85
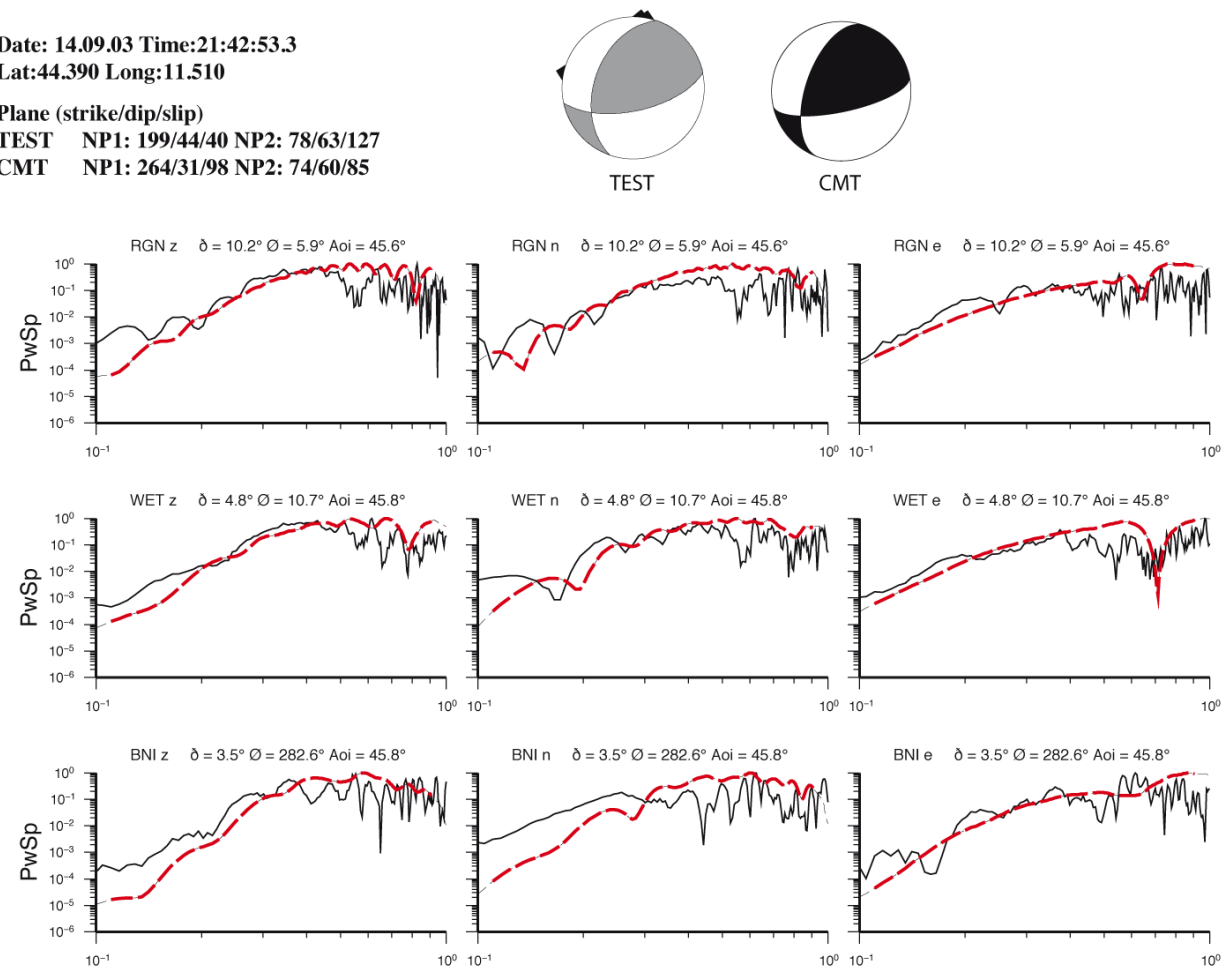

Date: 29.05.12 Time:07:00:03.0 Lat:44.820 Long:11.070

Plane (strike/dip/slip)

TEST NP1: 291/24/67 NP2: 136/68/99

CMT NP1: 299/38/66 NP2: 90/56/107
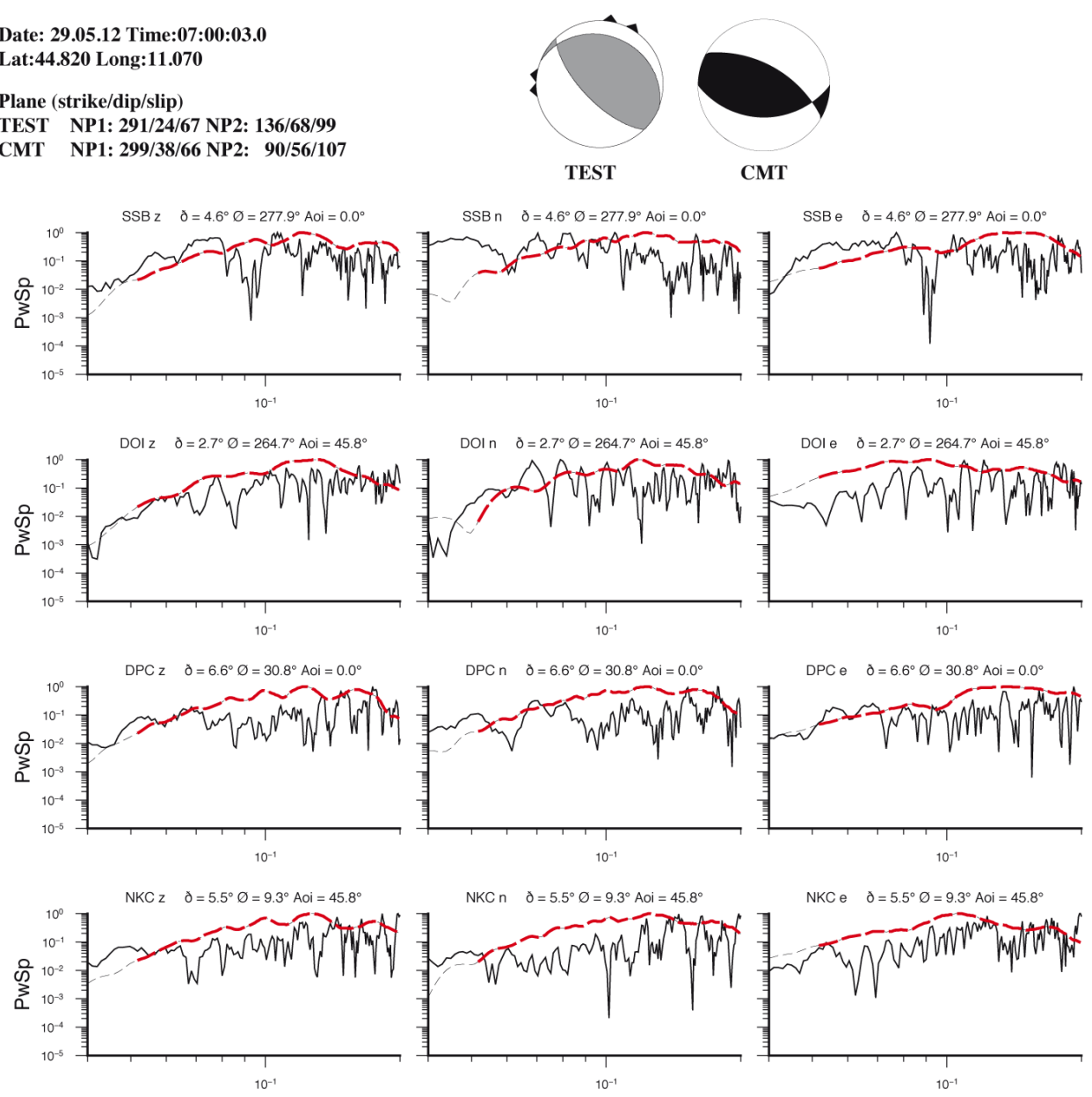

Figure 6. Examples of MT inversion solution for 2 recent earthquakes. Top: the northern Italy, September 2003 (left beachball) compared with the CMT-Harvard solution (right beachball). On the top left side are reported the origin time, the epicenter location used for the inversion and the two planes for our test and for the CMT solutions respectively. Below the spectral amplitude for the three station used. In each panel is reported the station code, seismogram directions (E-W/N-S) and synthetic (dark and dash lines) and observed (gray line) power spectra amplitude are shown. Distance $(\Delta)$ azimuth $(\Phi-)$ and take off angle (Aoi) between epicenter and station are also indicated. Bottom: the northern Italy, May 2012. 
a short period range (about 5-25 seconds) and p-wave arrival polarities to constrain the $\mathrm{P}$ - and $\mathrm{T}$ - axes. Our code runs as follows:

1) we generate Green's function for each sourcereceiver path using the normal mode summation [Woodhouse 1988] with the SURF96 [Herrmann 2013] algorithm, using fixed epicenter and depth; 2) from a Montecarlo simulation, we generate synthetic seismograms convolving Green's function with a set of 5,000 randomly computed synthetic moment tensors that were previously calculated and stored into a library; 3 ) we compute the theoretical P-wave polarities at each station for each synthetic MT; 4) the radial and transversal components of the synthetic data are rotated in the seismometer reference system and then convolved with the instrument response; 5) we estimate the normalized variance between the synthetic and observed power spectra amplitude and find the best solution among the minimum variance and best fit between the observed and theoretical P- wave polarities; 6) finally, we compute the seismic moment $\left(\mathrm{M}_{0}\right)$ for the best MT solution from the power spectra amplitudes.

This method has been tested on some recent earthquakes. In our tests we used a short period to reproduce the Wiechert seismograph transfer functions.
Figure 6 shows the results for a couple of events occurred in the Italian Peninsula: the September 14, 2003 , $\mathrm{M}_{\mathrm{w}}(\mathrm{CMT})=5.3$, northern Apennines earthquake and the May 29, 2012, $\mathrm{M}_{\mathrm{w}}(\mathrm{CMT})=5.8$, northern Italy. To reproduce a typical dataset available for historical earthquakes, we artificially reduced the station distribution to a small set with a very large azimuthal gap.

\section{MT solution of the 1917 earthquake}

First, we performed a quality check of the available seismograms based on i) reliable instrument parameters available for those stations and instruments and ii) the quality of the recordings (e.g., too small of a signal, a saturated signal, holes and contrasts with the trace recording with respect to the background color). After this quality check, we selected 7 seismograms from 5 European stations (Table 4) for digitization from raster files. Digitization was performed using Teseo $\underline{\underline{2}}$ software [Pintore et al. 2005] (Figure 7). The selected stations are located in western and central Europe between $3.6^{\circ}$ and $16.6^{\circ}$ distance from the epicenter (Figure 4).

The instruments from the 5 stations used in this work were Wiechert and Mainka horizontal seismographs. Both of these instruments are mechanical-type instruments, with constants summarized in Table 4 .

\begin{tabular}{|c|c|c|c|c|c|c|c|c|}
\hline Station & Instrument & Component & Latitude & Longitude & To & $\mathbf{h}$ & Vo & P-polarity \\
\hline UCC & Wiechert 1t & $\mathrm{n}-\mathrm{s}$ & 50.798 & 4.359 & 11.3 & 0.50 & 152 & -1 \\
\hline UCC & Wiechert 1t & e-w & & & 11.8 & 0.50 & 175 & 1 \\
\hline UPP & Wiechert 1t & $\mathrm{n}-\mathrm{s}$ & 59.858 & 17.627 & 9.1 & 0.35 & 188 & 0 \\
\hline UPP & Wiechert 1t & e-w & & & 9.1 & 0.35 & 187 & 0 \\
\hline ZAG & Wiechert 1t & nw-se & 45.829 & 15.994 & 7.0 & 0.50 & 200 & 1 \\
\hline FBR & Mainka & $e-w$ & 41.416 & 2.125 & 9.0 & 0.37 & 60 & 1 \\
\hline TOL & Wiechert 1t & ne-sw & 39.861 & -4.017 & 10.0 & 0.37 & 200 & 0 \\
\hline GTT & Wiechert $1 \mathrm{t}$ & $\mathrm{z}, \mathrm{ns}, \mathrm{ew}$ & 51.546 & 9.964 & & & & $1,1,-1$ \\
\hline POT & Wiechert 1t & ns,ew & 52.379 & 13.066 & & & & 1,1 \\
\hline RCR & Agamennone & nw-se, sw-ne & 41.898 & 12.480 & & & & $-1,1$ \\
\hline $\mathrm{MNH}$ & Wiechert 1t & $\mathrm{ns}$ & 48.150 & 11.620 & & & & -1 \\
\hline $\mathrm{CH} 1$ & Grablovitz ST & ns,ew & 44.316 & 9.318 & & & & $-1,1$ \\
\hline IS1 & Grablovitz GL & ns,ew & 40.740 & 13.943 & & & & $1,-1$ \\
\hline
\end{tabular}

Table 4. Data used for the power spectra computation and MT estimation. Top: latitude, longitude, instrument type, instrument response parameters and polarities for each station and instrument component used for power spectra computation. Bottom: additional polarities used to constrain the T- and P- axes. Polarities include polarity of the first P-arrival and of the instrument. Polarity equal to 0 are not used. Instrument: Agamennone $=$ Agamennone horizontal pendula seismograph; Grablovitz GL $=$ Grablovitz geodynamic pendula; Grablovitz ST = Grablovitz seismic tank; Mainka = Mainka horizontal seismograph; Wiechert 1t $=1$ ton Wiechert horizontal seismograph. 


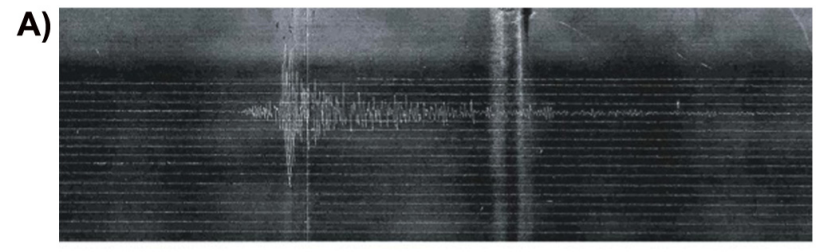

B)

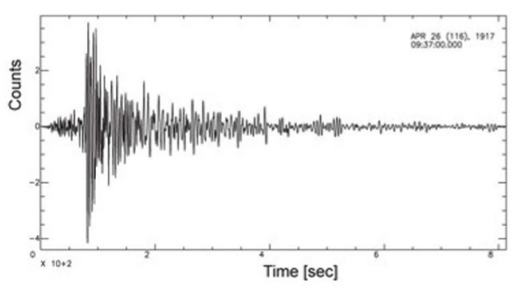

Figure 7. Example of a raster (A) image: the seismogram was recorded on smoked paper by the Wiechert seismograph at Zagabria station, NW component for the April 26, 1917, earthquake. Vectorized image (B) derived from the raster image using teseo2, a neural network based program, which converts raster images into sampled series.

We read 16 reliable P-wave first arrival polarities from the 28 seismograms to constrain the P- and T-axes.

The best fit moment tensor solution (Figure 8) for the 1917 High Tiber Valley earthquake results in a normal fault mechanism with the following planes (strike/dip/slip): 147/29/-94 and 331/62/-88. Figure 8 shows the fit between the amplitude of the normalized power spectra of the observed (black lines) and the synthetic seismograms (dashed lines) for each station and the component used for the inversion. As described above, the inversion was performed in a relatively short frequency range; in this case, we selected frequencies between 0.05 and $0.2 \mathrm{~Hz}$ (red thick dashed lines). The station code, the component, the epicentral distance, and the azimuth and incidence angles are indicated on the top of each plot. The beachball represents the best double couple moment tensor solution, and the black flags indicate the azimuthal direction of the used stations. The orientations of the principal planes and axes are reported on the bottom right of the figure. The seismic moment is calculated using the absolute amplitude power spectra. From the Kanamori [1977] relationship, $\mathrm{M}_{\mathrm{w}}=\log \mathrm{Mo} / 1.5-10.7$, we calculated a moment magnitude $\mathrm{M}_{\mathrm{w}}=5.5$.

\section{Discussion and final remarks}

This paper proposes a method to compute the MT solution for earthquakes of the pre-WWSSN era to solve the problem of large uncertainties in the determination of arrival times because of lack of synchronization of seismic station clocks. This method was applied to the High Tiber Valley earthquake of April 26,1917 , the most important event of the 20th century of this area.

Our code resulted in a MT solution consistent with the tectonics of the region, using only amplitude spectra and p-wave first arrival polarities from the sparse historical seismological records that are available.

Additionally, the significant uncertainties in phase readings introduced by the poor clock synchronization of the early seismographs and by the use of uncalibrated general 1D Earth models do not significantly affect the MT solution. The phases shift uncertainties caused by poor clock synchronization and uncalibrated general 1D Earth model, may introduce significant uncertainties into the final solution when using a time do-
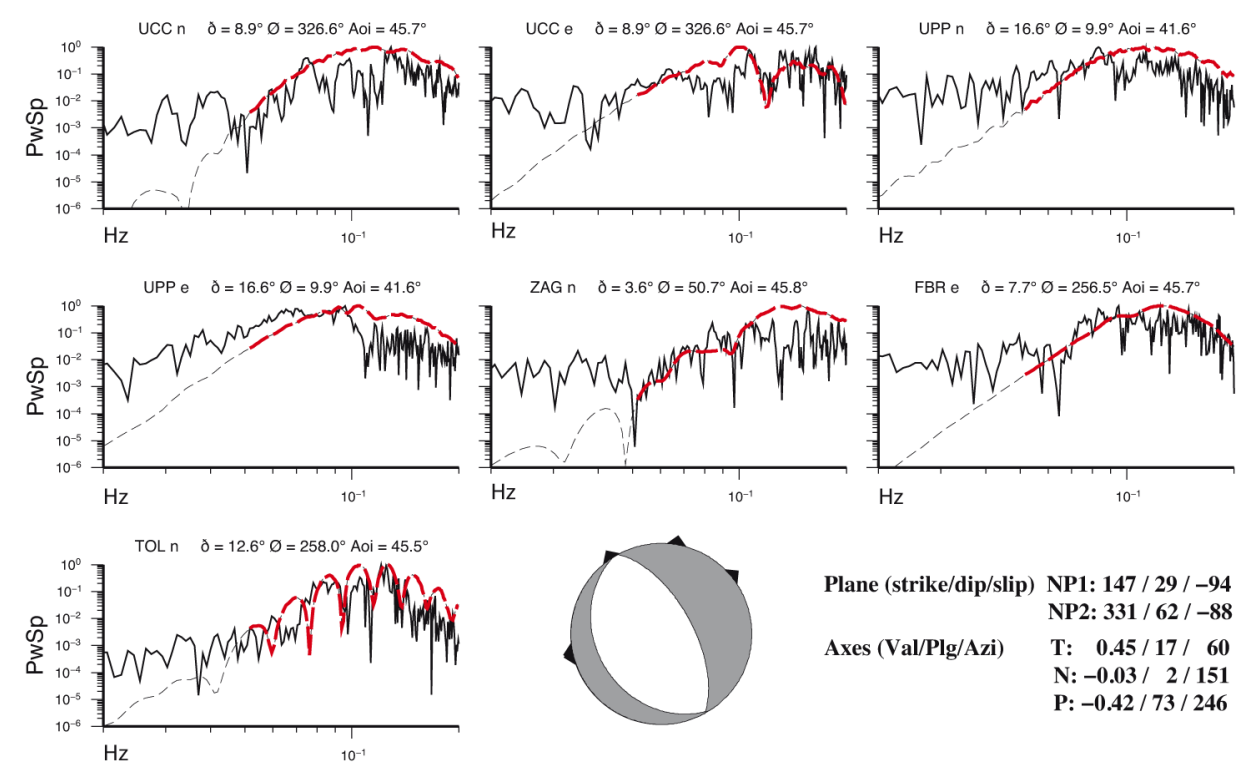

Figure 8. Power spectra amplitudes of the stations used for MT inversion for the 1917 Monterchi earthquake. Station codes, seismogram directions (E-W/N-S) and synthetic (dark and dash lines) and observed (gray line) power spectra amplitude are shown. Distance $(\Delta)$ azimuth $(\Phi-)$ and take off angle (Aoi) between epicenter and station are also indicated. 
main moment tensor inversion approach.

The application of our method to compute the MT of the 1917 earthquake showed an excellent correspondence between the orientation of both the MT nodal planes $\left(147^{\circ}\right.$ or $\left.331^{\circ}\right)$ and the strike of the macroseismic box (Figure 3) $\left(157^{\circ}\right)$. This result is also in good agreement with the fissures in the ground observed by Oddone [1918] close to Monterchi and oriented approximately NW-SE.

The macroseismic epicenter was recalculated with the newly released Boxer 4.0 code [Gasperini et al. 2010], and the new location was found to be only a few kilometers west of the epicenter of the CFTI4med (see Data and sharing resources).

The instrumental location calculated with NLL is approximately $20 \mathrm{~km}$ north of the macroseismic epicenter calculated using Boxer 4.0. The new location is coherent with the seismicity of the area Such difference between the instrumental and the macroseismic locations is also observed for earthquakes occurring in the first half of the 20th century, where macroseismic and instrumental epicenters were located $20 \mathrm{~km}$ and more apart. This difference may arise because of the abovedescribed uncertainties of old instrumental data as well as the low density of seismic stations south of the epicentral area.

Both solutions, namely, the instrumental and macroseismic epicenters, are consistent with the seismotectonic background. The macroseismic location confirms the epicenter in the basin.

The $M_{w}=5.5 \pm 0.2$ computed from MT is lower than the $M_{w}=5.9 \pm 0.1$ derived from macroseismic observations. This discrepancy may be due to the behavior of the mechanical seismometers, which act like a high-pass filter and exhibit very low sensitivity to phases with periods of 20 seconds or longer.

The kinematics of the 1917 earthquake, as described in this paper, are coherent with the kinematics of normal faults bordering the basin and thus with the focal mechanisms of the modern instrumental earthquakes that indicate a SW-NE active regional extension.

Since the Pliocene, the basin's evolution has been driven by a complex extensional fault system: the AtF geometry is clearly imaged in seismic reflection profiles [Barchi et al. 1998, Barchi and Ciaccio 2009, Mirabella et al. 2011] and is consistent with movements along an east-dipping extensional fault. The AtF is potentially one of the rare examples of an active LANF (dipping $<30^{\circ}$ ). The possibility that larger (i.e., moderate) seismicity may be generated by a segment of the AtF, i.e., of a regional LANF, has been proposed in the literature [Brozzetti et al. 2009], and abundant microseismicity, recorded by temporary local networks along the AtF surface, demonstrates that the LANF is currently active [Piccinini et al. 2003]. The NE-dipping splays of the AtF have been indicated as responsible for the 1352 and 1917 earthquakes by Delle Donne et al. [2007], DISS (see Data and sharing resources), Basili et al. [2008] and Brozzetti et al. [2009]: in fact, the surface faulting observed during the 1917 earthquake occurred along the trace of the active Anghiari fault, the normal NE-dipping fault bordering the western side of the Sansepolcro basin belonging to the Umbria Fault System [Barchi and Ciaccio 2009].

Finally, from a seismotectonic perspective, we can assert that the new moment tensor of the 1917 earthquake is consistent with the geodynamics of the region. Nevertheless, the uncertainties in the earthquake locations do not allow to clearly associate a seismotectonic structure with the epicenter in order to fix between the two nodal planes. Moreover, it is possible to associate the high-angle plane dipping toward the east with a synthetic splay of the AtF [Chiaraluce et al. 2014] and the low-angle plane dipping toward the west, antithetical to the AtF (e.g., the basal geometry of the Gubbio fault; Mirabella et al. [2004]).

This work shows that the study of "historical earthquakes" using modern techniques needs to address significant "uncertainties". For this reason, a multidisciplinary approach can reduce the uncertainties of the results by highlighting the coherent parameters.

Reliable location, moment magnitude estimation and focal mechanism determination for historical earthquakes - like the 1917 Monterchi earthquake - help to characterize seismotectonic areas which generated only few strong earthquakes in the past century and in the pre-instrumental period (e.g. 1352). Consequently, any improved characterization of such areas, are relevant for seismic hazard assessment and risk.

Acknowledgements. We wish to thank the Sismos Team for vectorization of seismograms and the anonymous reviewer for its careful review. We are also especially grateful to Gianfranco Vannucci for constructive comments and suggestions on the parametrization of the macroseismic data.

\section{References}

Barchi, M.R., A. De Feyter, M.B. Magnani, G. Minelli, G. Pialli and B.M. Sotera (1998). Extensional tectonics in the Northern Apennines (Italy): Evidence from the CROP03 deep seismic reflection line, Mem. Soc. Geol. It., 52, 527-538.

Barchi, M.R., and M.G. Ciaccio (2009). Seismic images of an extensional basin, generated at the hangingwall of a low-angle normal fault: The case of the Sansepolcro basin (Central Italy), Tectonophysics, 479, 285-293.

Basili, A., G. Smriglio and G. Valensise (1984). Proce- 
dure di determinazione ipocentrale in uso presso l'Istituto Nazione di Geofisica, Atti III Convegno G.N.G.T.S., Roma, 875-884 (in Italian).

Basili, R., G. Valensise, P. Vannoli, U. Fracassi, S. Mariano, M.M. Tiberti and E. Boschi (2008). The Database of Individual Seismogenic Sources (DISS), version 3: summarizing 20 years of research on Italy's earthquake geology, Tectonophysics, 453 (1-4), 20-43.

Bernardi, F., J. Braunmiller and D. Giardini (2005). Seismic Moment from Regional Surface-Wave Amplitudes: Applications to Digital and Analog Seismograms, B. Seismol. Soc. Am., 95 (2), 408-418; doi: $10.1785 / 0120040048$.

Bernardi, F., A. Lomax, A. Michelini, V. Lauciani, A. Piatanesi and S. Lorito (2015). Appraising the Earlyest earthquake monitoring system for tsunami alerting at the Italian candidate Tsunami Service Provider, Nat. Hazards Earth Syst. Sci. Discuss., 3, 2913-2952; doi:10.5194/nhessd-3-2913-2015.

Boncio, P., and G. Lavecchia (2000). A structural model for active extension in Central Italy, J. Geodyn., 29, 233-244.

Brozzetti, F., P. Boncio, G. Lavecchia and B. Pace (2009). Present activity and seismogenic potential of a lowangle normal fault system (Città di Castello, Italy): Constraints from surface geology, seismic reflection data and seismicity, Tectonophysics, 463 (1-4), 31-46.

Cavasino, A. (1927). Bollettino sismico, Microsismi, fasc. 4, Anno 1917, Roma (in Italian).

Chiarabba, C., L. Jovane and R. DiStefano (2005). A new view of Italian seismicity using 20 years of instrumental recordings, Tectonophysics, 395, 251-268.

Chiaraluce, L., C. Chiarabba, C. Collettini, D. Piccinini and M. Cocco (2007). Architecture and mechanics of an active low-angle normal fault: Alto Tiberina Fault, Northern Apennines, Italy, J. Geophys. Res., 112, B10310; doi:10.1029/2007JB005015.

Chiaraluce, L., A. Amato, S. Carannante, V. Castelli, M. Cattaneo, M. Cocco, C. Collettini, E. D’Alema, R. Di Stefano, D. Latorre, S. Marzorati, F. Mirabella, G. Monachesi, D. Piccinini, A. Nardi, A. Piersanti, S. Stramondo and L. Valoroso (2014). The Alto Tiberina Near Fault Observatory (Northern Apennines, Italy), Annals of Geophysics, 57 (3), S0327; doi:10.4401/ag-6426.

Ciaccio, M.G., S. Pondrelli and A. Frepoli (2006). Earthquake fault-plane solutions and patterns of seismicity within the Umbria Region, Italy, Annals of Geophysics, 49 (4/5), 987-1002.

Collettini, C., and R.E. Holdsworth (2004). Fault zone weakening and character of slip along low-angle normal faults: insights from the Zuccale fault, Elba, Italy, J. Geol. Soc. London, 161 (6), 1039-1051.
Delle Donne, D., L. Piccardo, J.K. Odum, W.J. Stephenson and R.A. Williams (2007). High- resolution shallow reflection seismic image and surface evidence of the Upper Tiber Basin active faults (Northern Apennines, Italy), B. Soc. Geol. Ital., 126 (2), 323-331. Ferrari, G., and N.A. Pino (2003). Euroseismos 2002-2003, a project for saving and studying historical seismograms in the Euro-Mediterraneanarea, Geophys. Res. Abstr., 5, 05274.

Gasperini, P., F. Bernardini, G. Valensise and E. Boschi (1999). Defining seismogenic sources from historical earthquake felt reports, B. Seismol. Soc. Am., 89, 94-110.

Gasperini, P. (2004). Boxer User Guide, version 3.3, manual33.pdf.

Gasperini, P. (2008). Boxer 3.3 recalibration tutorial, recalibration_tutorial.pdf.

Gasperini, P., G. Vannucci, D. Tripone and E. Boschi (2010). The location and sizing of historical earthquakes using the attenuation of macroseismic intensity with distance, B. Seismol. Soc. Am., 100 (5A), 2035-2066; doi:10.1785/0120090330.

Herrmann, R.B. (2013) Computer programs in seismology: An evolving tool for instruction and research, Seismol. Res. Lett., 84, 1081-1088; doi:10.17 85/0220110096.

Kanamori, H. (1977). The energy release in great earthquakes, J. Geophys. Res, 82, 2981-2987.

Kennett, B.L.N. (2005). Seismological Tables: ak135, Research School of Earth Sciences, The Australian National University, 290 p.

Lomax, A. (2005). A reanalysis of the hypocentral location and related observations for the great $1906 \mathrm{Cal}-$ ifornia earthquake, B. Seismol. Soc. Am., 95, 861-877; doi:10.1785/0120040141.

Michelini, A., B. De Simoni, A. Amato and E. Boschi (2005). Collecting, Digitizing, and Distributing Historical Seismological Data, Eos Transactions AGU, 86 (28), 261-266.

Mirabella, F., M.G. Ciaccio, M.R. Barchi and S. Merlini (2004). The Gubbio normal fault (Central Italy): geometry, displacement distribution and tectonic evolution, J. Struct. Geol., 26, 2233-2249; doi:10.10 16/j.jsg.2004.06.009.

Mirabella, F., F. Brozzetti, A. Lupattelli and M.R. Barchi (2011). Tectonic evolution of a low-angle extensional fault system from restored cross-sections in the Northern Apennines (Italy), Tectonics, 30 (6); doi:10. 1029/2011TC002890.

Musson, R.M.W. (1996). Determionation of parameters for historical earthquakes, Annali di Geofisica, 39 (5), 1041-1047

Oddone, E. (1918). Il terremoto dell'Alta valle del Te- 
vere del 26 aprile 1917, Bollettino della Società Sismologica Italiana, 21, 9-27 and tables I-IV (in Italian).

Okal, E.A., and D. Reymond (2003). The mechanism of great Banda Sea earthquake of 1 February 1938: applying the method of preliminary determination of focal mechanism to a historical event, Earth Planet. Sc. Lett., 216 (1/2), 1-15.

Pasolini, C., D. Albarello, P. Gasperini, V. D’Amico and B. Lolli (2008). The attenuation of seismic intensity in Italy, Part II: Modeling and validation, B. Seismol. Soc. Am., 98, 692-708.

Piccinini, D., M. Cattaneo, C. Chiarabba, L. Chiaraluce, M. De Martin, M. Di Bona, M. Moretti, G. Selvaggi, P. Augliera, D. Spallarossa, G. Ferretti, A. Michelini, A. Govoni, P. Di Bartolomeo, M. Romanelli and J. Fabbri (2003). A microseismic study in a low seismicity area of Italy: the Città di Castello 2000-2001 experiment, Annals of Geophysics, 46 (6), 1315-1324.

Piccinini, D., N. Piana Agostinetti, P. Roselli, M. Ibs-von Seht and T. Braun (2009). Analysis of small magnitude seismic sequences along the Northern Apennines (Italy), Tectonophysics, 476, 136-144.

Pintore, S., M. Quintiliani and D. Franceschi (2005). Teseo: A vectoriser of historical seismograms, Comput. Geosci., 31, 1277-1285.

Scognamiglio, L., E. Tinti and A. Michelini (2009). RealTime Determination of Seismic Moment Tensor for the Italian Region, B. Seismol. Soc. Am., 99 (4), 2223-2242; doi:10.1785/0120080104.

Wells, D.L., and K.J. Coppersmith (1994). New empirical relationships among magnitude, rapture length, rupture width, rupture area, and surface displacement, B. Seismol. Soc. Am., 84, 974-1002.

Woodhouse, J.H. (1988). The calculation of eigenfrequencies and eigenfunctions of the free oscillations of the Earth and the Sun, In: D.J. Doornbos (ed.), Seismological Algorithms, Computational Methods and Computer Programs, London, Academic Press, 321-370.

Zahradnik, J., K. Jansky and K. Papatsimpa (2001). Focal Mechanisms of Weak Earthquakes from Amplitude Spectra and Polarities, Pure Appl. Geophys., 158, 647-665.

\section{Data and sharing resources}

The raster images of the seismograms used in this study were collected as part of the SISMOS and EuroSeismos projects (http://storing.rm.ingv.it/es_web; last accessed May 2016) and are stored in the Sismos database (http: / / seismogramrequest.rm.ingv.it; last accessed May 2016).

The seismic bulletins and instrumental constants used in this study were collected as part of the Sismos,
EuroSeismos and GEM projects (http: / / sismos.rm.ingv. it/en/index.php/bulletins; last accessed May 2016).

The catalogue of the revised recent Italian seismicity is listed: B. Castello, G. Selvaggi, C. Chiarabba and A. Amato (2006). CSI Catalogo della sismicità italiana 1981-2002, versione 1.1. INGV-CNT, Roma: http:/ / csi.rm.ingv.it/ (last accessed December 2014).

The CFTI4Med, Catalogue of strong earthquakes in Italy (461 B.C. - 1997) and Mediterranean area (760 B.C.-1500), INGV-SGA by E. Guidoboni, G. Ferrari, D. Mariotti, A. Comastri, G. Tarabusi and G. Valensise (2007) was searched using: http:/ / storing.ingv.it/cfti4 med/ (last accessed December 2015).

The Parametric catalogue of Italian earthquakes (CPTI04; CPTI Working Group 2004) was searched using: http:/ emidius.mi.ingv.it/CPTI04/ (last accessed December 2014).

Data of the seismogenic sources used in this study are from the Database of individual seismogenic sources (DISS), v 3.1.1: http:/ / diss.rm.ingvitit diss / (last accessed December 2015).

The recent seismicity mapped in this study is available from the Italian seismological instrumental and parametric database (ISIDe database; http: / / iside.rm. ingv.it).

For GMT, we used: http:/ / gmt.soest.hawaii.edu/ .

The earthquake relocation program NonLinLoc is available at http://alomax.free.fr/nlloc/.

The neural networks that we used are from http://teseo.rm.ingv.it/ source/ (last accessed December 2016).

The seismic analysis code (SAC) that we used is from http:/ / www.iris.edu/files/sac-manual/ (last accessed May 2014).

\footnotetext{
${ }^{\star}$ Corresponding author: Fabrizio Bernardi, Istituto Nazionale di Geofisica e Vulcanologia, Centro Nazionale Terremoti, Rome, Italy; email: fabrizio.bernardi@ingv.it.

(C) 2016 by the Istituto Nazionale di Geofisica e Vulcanologia. All rights reserved.
} 